\title{
Education 4.0 in cartography: an integrated e-learning materials portal for cartography and digital mapping course
}

\author{
Daniel Abdul Halim a , Abdul Rauf Abdul Rasam, ${ }^{\text {b,* }}$ \\ ${ }^{a}$ Centre of Studies for Surveying Science and Geomatics, Faculty of Architecture, Planning and Surveying, Universiti Teknologi \\ MARA, Shah Alam, Selangor, Malaysia-danielabdulhalim95@gmail.com \\ ${ }^{b}$ Centre of Studies for Surveying Science and Geomatics, Faculty of Architecture, Planning and Surveying, Universiti Teknologi \\ MARA, Shah Alam, Selangor, Malaysia-rauf@uitm.edu.my \\ * Corresponding Author
}

\begin{abstract}
World's technology development is defined by the level of advancement in the current industrial sector that is called industrial revolution (IR). The evolution of the technologies may affect the learning system for educators and learners. Throughout the years, student discovering troubles to have an effective learning method for their subject. To keep up the mushroom growth of technologies, e-learning has been identified as the best learning method that suits with the current generation's way of learning. This paper aimed at designing and developing an integrated e-learning material portal for assisting university students of Centre of Study for Surveying Science and Geomatics (PPSUG) University of MARA (UiTM) Malaysia to have a helpful learning process in Cartography subject. The study conducted in three main objectives: i. To study the user requirement, ii. To create and design the portal iii. To test the proposed portal using WordPress platform. The finding has revealed that most of the respondents significantly agreed and willingly to have an integrated e-learning portal to assist in the subject. The proposed portal offers special functions for learning materials process in particular integrating all learning materials in one platform such online notes, assignments, lab work sheets and other benefits that are easy - free to access and user friendly knowledge transfer for the public. The portal it still needs using the university hosting for comprehensive practice among the SUG students.
\end{abstract}

Keywords: cartography, mapping, e-learning, industrial revolution (IR) 4.0

\section{Introduction}

Learning is the procedure securing of information or aptitudes through study, examination, experience, or being instructed particularly at school and college. Traditional learning and e-learning are two different types of acquiring knowledge. Traditional learning occurs in a physical location where students and teachers can communicate, while e-learning takes place in an e-space that includes a server and an internet browser interface. (Singh, et al, 2009). Conventional classroom learning is a significant form of conventional learning and has long been embraced and used in various colleges and universities while electronic or e-learning is learning method by using digital technology to retrieve educational material from outside of the traditional classroom. Both types of learning method have their own advantages and disadvantages.

Zhang, et al. (2004) stated the main advantage and disadvantage of traditional learning and e-learning method. The advantages of traditional learning are the interaction between the students and educator, instant assessment, skill development and socialization. The advantages of e-learning such as easy sharing of information, making course materials available at any time, cost-effective for learners, unlimited access to knowledge and helpful for educator. The disadvantages of traditional learning can be noticed in the limited size of classroom, time and location constraints, accessibility of source material and expensive to deliver course material. The disadvantages of e-learning such as it need new skill from the learner and educator for the learning method to perform, affordability of the e-learning system, minimal social interaction, and lack of immediate feedback. To align the education system with the latest technology development, e-learning is more suitable learning and teaching method especially for students and educator in this 21 st century.

World's technology development is classified by the level of advancement in the current industrial sector. Now the fourth industrial revolution (4IR) is built on the third. It is defined by a convergence of technology that blurs the distinctions between the physical, electronic, and biological realms (Schwab, 2016). The 4IR represents new ways in which technologies such as Artificial Intelligence (AI), digitisation, automation, and Internet of Things (IoT) are embedded in our daily experience. This phenomenon will fundamentally alter the way we live, work, study and relate to one another. To make sure the education system is corresponding with IR4.0, thus Education 4.0 was created. Education 4.0 is an answer to the demands of IR4.0, in which humans and machines work together to create exciting options. (Aziz Hussin, 2018). The new learning system encourages learners to focus on their skills and knowledge that are needed, but also to identify the source of knowledge and the skills to 
learn, adapt and apply in quick cycles especially with vast information of the IoT.

The advent of technology continues to change and transform the teaching method as well as the setting of the learning experience. There will, in fact, be additional changes in the future. (Ethan Dunwill, 2016). Some of the frequent improvements that organizations have recognized include posting grades and assignments online, team projects completed via collaborative technology, coursework done electronically and published through school portals, students storing their work in the cloud rather than on floppy disks or paper, and teachers, parents, students, and officials connecting through social media sites built expressly for education.

The efforts of the Malaysian educational circle show a decent start in the education system riding the 4IR's rush to train future generation graduates with skills and knowledge to create productivity and contribute to the economic development of the country. The program is called Malaysian Higher Education Programme 4.0 (MyHE 4.0) which promotes the multifarious of students ' positions as information curators, content producers, web-based connectors as an open international curriculum and resource guide educators. MyHE 4.0 accentuate higher order thinking skills (HOTS) than lower order thinking skills (LOTS) the main goal of the learning process is where learners are required to acquire new skills, knowledge and behaviours as well as build new knowledge of their own. Instead of only acquiring data, learners should also actively contextualise and generate data based on personal experience and environmental participation.

A potential ready curriculum fosters transformative 21 stcentury Learning \& Teaching (L\&T) delivery by revamping learning spaces, using the newest 4IR technologies, and fostering holistic learning toward the accomplishment of learning outcomes. Redesigning higher education initiatives are one of the approaches to achieve the focus of the future ready curriculum. MOHE has introduced several initiatives that highlight the transformations 2u2i, iCGPA, APEL, Malaysia MOOC, GAP Year, CEO@Faculty, MEA and My E-Portfolio (Tapsir \& Puteh, 2018). One solution is revolutionary L\&T delivery. Future ready Curriculum support 21st century L\&T implementation which involves selfdetermined education, peer-oriented learning, virtualbased learning, and experiential learning which advocates learning without lectures and learning outside the classroom.

Different learning methods can be used in education to enhance the learning process. Because educators are responsible for helping countries to achieve a high level of education, however, they should use approaches that not only communicate information, but also inspire students to think at higher levels. E-learning is one of the most suitable methods for effective learning that will encourage student's high order thinking skill and meet the needs corresponding to MoHE's MyHE 4.0 and Education 4.0. Integration of all materials in Cartography is a main agenda in this study towards education 4.0 in PPSUG, UiTM. The objectives of the study are:

- To study the user requirement on the proposed integrated e-learning system of Cartography among Geomatic Science students of UiTM Shah Alam.

- To develop and design an integrated e-learning materials system for Cartography.

- To evaluate the proposed system with fulfilling the Cartography student's requirement in UiTM Shah Alam.

\section{Literature review}

\subsection{IR 4.0 in Malaysian Education}

According to the World Economic Forum, the Fourth Industrial Revolution (4IR) has been underway since the beginning of the twenty-first century. The universal and mobile connectivity, cheaper, smaller, and smarter sensors, and artificial and machine learning are all part of this dramatic revolution (Schwab, 2017). The 4IR concept is characterised as a revolutionary transition based on new and diversified technologies (MinHwa Lee, 2018; Jazdi, 2014). This term does not describe the technological paradigm uniformly. (Lee et al., 2018).

The 4IR can be defined as the revolutionary transformation that occurs as IT spreads throughout all industries, that is, primary, secondary, and tertiary industries. In other words, this is the result of IT's horizontal expansion. As a result, the 4IR emphasises on the creative connection between technology and the market in all IT-based enterprises, that is, the creative and open combination of technology and the market through open innovation, or growth based on the open business model (Yun, 2017). It can also include the factory automation, cyber-physical systems, self-organization, new distribution and procurement systems, new product and service creation systems, adapt to human demands, and employee engagement (Lasi, 2014).

In the contents of education, the academic learning environment needs IR4.0 where humanity and technology are aligned to enable new possibilities (Aziz Hussin, 2018). Education 4.0 embraces a new vision of education that allows students not only to learn the skills and knowledge they need, but also to identify the source of learning these skills and knowledge. Learning is built around them as to where and how to learn and track their performance through data-based customization. Peers are becoming very critical in their education. Students learn together and from each other, while teachers take on the role of facilitators in their learning. 
Malaysia adapts the IR 4.0 through Malaysian Higher Education Programs (MyHE), The programs have undergone significant transformation over the years. Beginning with MyHE 1.0, which focuses on the instructor as a source of knowledge by using the chalk and talk teaching process. Start with MyHE 2.0, which lays out the use of modern engineering activities in classrooms and recognizes students as receivers of information that regurgitates and reacts to knowledge. MyHE 3.0 promotes innovative educational methods by encouraging students to discuss real-world problems and work together on social learning platforms. And now, MyHE 4.0 enables students to diversify their positions as curators of information, content producers, link makers and the internet as an open global curriculum and educators as a resource guide.

In the context of e-learning, the knowledge-based economy has exhibited a pervasive and ever-increasing demand for innovative ways of providing education in recent years, leading to dramatic changes in learning technologies and organizations, These radical changes in learning needs and technology are fueling a transition in modern learning in the era of the Internet, commonly referred to as e-learning (Shea, 2002). Web-based training is now being used as another alternative to faceto-face education. As a matter of fact, its use increases immediately with the expansion of the student quantity. This has influenced teachers to obtain interactive content full of multimedia as it has been shown to have a significant impact on the way of learning. The influence of online journals and wikis was also discussed on the joint effort and reflection by students, and it was accounted for the positive outcome of both of them.

Cheng, (2006) and Fitzpatrick, (2012) expanded the term to include "everything given, enabled, or mediated by electronic technology for the explicit goal of learning.". Thus, according to Masters (2009), the letter "e" in elearning should not stand for electronic; rather, it should stand for "evolving, enhanced, everywhere, every time, but everyone." In fact, the quotation of Masters, (2009) shows most of the advantages of e-learning for learners and instructors. As the modern economy necessitates more individuals learning new knowledge and skills in a timely and effective manner, advancements in computer and networking technologies are giving a variety of tools to assist learning in a more personalised, adaptable, and an on-demand way (Zhang et al., 2004). Drucker, (2000) believed that e-learning is concerned not only with providing easy access to learning resources, anytime through a repository of learning resources, but also with supporting features such as personalization of learning goals and active and passive cooperation between students and between instructors and students.
In UiTM, is not left to introduce I-Learn program for all students in line with current technology developments. Admitting that there is a positive impact on student achievement, researchers conducted a pilot study of 20 students to obtain a rough description and the program answer in UiTM. This research focuses on only two variables, namely the technology and the characteristics of the learners. Due to the difficulty of accessibility and lack of awareness of this system they choose not to use ILearn (Setapa, 2012).

E-learning offers distance learning via the Internet, provides opportunities for students via interactive learning experience and efficient learning. Distance learning students will be able to study a lot more, share information, and acquire as many facts about the courses as possible due to e-learning (Guha, and Maji, 2008). Researchers believe that, in accordance with the implementation of I-Learn and Blended Learning at UiTM, this study will provide advantages and insights to decision-makers and the national education body. A study by Arani (2001) stated that computers have had a dramatic impact on our society, especially in the field of education. According to Ertmer et al. (1999), students who have successful computer experiences are better prepared to contribute effectively in a computerdominated community.

\subsection{E-learning of Cartography and Geomatics}

With the increasing importance and demand for geographic information in mapping industry and studies, many approaches have been made by researchers to improve understanding and ways in gaining knowledge for Geomatics courses. Previous studies have shown the related studies and projects that used online learning method for Geomatics courses (Marion Werner et al., 2005; Frančula et al., 2010; Robinson et al., 2015). Marion Werner et al. (2005) developed e-learning materials in GIS-technology and Cartography - towards an open-content solution, this GITTA (Geographic Information Technology Training Alliance) is an interactively designed, IT-based and multilingual collection of learning materials which can be used for various courses in Geomatics and Cartography studies, environmental or GI sciences.

The other project called Thematic Cartography Course using MOODLE (Modular Object-Oriented Dynamic Learning Environment) and CartouCHe (Cartography for Swiss Higher Education) (Frančula et al,. 2010) that offer all kinds of user knowledge of thematic Cartography. A new approach to online teaching or the massive online open course (MOOC) has been also introduced by Anthony et al. (2015) as a distinct from conventional online classes as they help thousands of learners through content and assessment processes fro free. These platforms allow students to extend their basic knowledge and case studies to provide in-depth, project-related work in specific fields. Nowadays, many innovative learning 
and teaching approach have been introduced and applied in Cartography in particular during the global pandemic towards providing fair, educational opportunities for everyone, including online learning systems, open source platform, virtual environment, augmented reality (AR) and Mobile Learning (Liu et al., 2020; Omar et al., 2021; Wan Hairi et al., 2021; Abdul Basir and Abdul Rasam, 2019; German and Luz, 2018; Carlos et al, 2018; Moris 2018).

\section{Materials and methods}

Figure 1 shows the essential steps in the research methodology on how to acquire properly the goal of this study, starting from need assessment to system evolation.

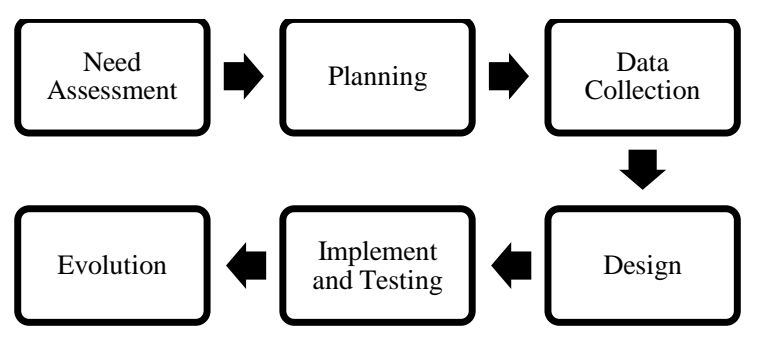

Figure 1. Research methodology

\subsection{Phase of Need Assessment and Planning}

The first phase to be taken performing a pilot study in order to understanding of current education system provided and problems experienced by referring to science Geomatic students as a user of current UiTM, Shah Alam's education system. All the questions were well-prepare based on the respondent needs. Meanwhile, project planning is a process that involves a provision at the outset to select the area and selection of hardware and software. The preparation stage focuses mainly on the work of the necessary project.

UiTM Shah Alam is chosen as the study area because the targeted audience is the SUG students who are currently using the education system of the UiTM and taking advanced Cartography in their study subject. The hardware and software are utilized in this study are Acer Aspire laptop and Bitnami. Bitnami used as a repository of web applications and technology stacks installers and software packages as well as digital appliances. Bitnami stacks are available for WordPress, Drupal, Joomla web applications! Redmine, AbanteCart, PrestaShop, Magento, and many more. WordPress will be part of a WordPress stack, along with the MySQL database for data management, the Apache Web server for serving pages, the OpenSSL library for basic cryptographic tasks, and PhpMyAdmin for MySQL administration (Fred Meyer, 2018; Mat, 2002; Imran, 2017)

\subsection{Phase of Data Collection}

Primary data for this study were collected through interviews and questionnaires. Interviews are intimate and unstructured interviews aimed at establishing the attitudes, feelings and perceptions of the respondent with regard to a specific purpose of the project. The questionnaire described in this study was performed using Google Forms, indicating that questionnaires are produced as a form of data collection that is superficially attractive largely due to low cost, but the response rate is usually relatively small unless the recipients are very interested in the subject of the survey. The questionnaires were distributed among the students in 2019.

\subsection{Phase of Design, Implementation and Testing}

The program was developed or designed during the design phase to meet the requirements defined during the phases of the need assessment. The specifications defined during the need evaluation process resulting from the questionnaire and then translated into a system design report that describes the system design accurately and can be utilised as an input for system design. Follow the step taken by the software developer before moving to the implementation and testing phase to construct the application.

\subsection{Phase of Evolution}

This phase includes monitoring and evaluation based on the changes needed. The phase was carried out when respondents give their opinion and advice to improve the system performance, add new features or meet additional user requirements if they wish. As the program entered the implementation process, the target respondent will send a recommendation. All the advice was gathered as the process improvisation was taken on the bases of the feedback obtained. As anticipated, this system greatly assisted students in their education system.

\section{Result and discussion}

This study was conducted to produce a web-based application for facilitating UiTM students, especially the SUG students to have a helpful learning method in Cartography. This portal offers an integrated learning platform to ease the student in obtaining the knowledge and the learning materials for Cartography subject.

\subsection{User Requirement on the Proposed System}

Need assessment was conducted to see what the user requirements towards applying integrated learning system for Cartography in order to ease to the student in acquiring knowledge on Cartography and mapping course. The forms were distributed to randomly respondents and received the respondents from variety of semester, and academic background, especially the students who have taken the subject. From 30 students, $63.3 \%$ of the respondents are from semester 7 and another $36.7 \%$ are from semester 8 . There are $70 \%$ of the respondents are from a Diploma for their academic background, $13.3 \%$ are from matriculation, and $10 \%$ are from STPM and $6.7 \%$ of the respondents are from the Foundation. 
Next, respondents were asked about their satisfaction level on the existing Cartography learning system. The satisfaction level was determined by numbers 1 to 5 as an interval scale. Starting from very dissatisfied followed by Not Satisfied (1), Slightly Satisfied (2), Satisfied (3), Very Satisfied (4) and Extremely Satisfied (5). Several issues regarding existing Cartography learning system were also asked the respondent. Figure 2 shows most of the respondents are satisfied (rank 4 and 5) in acquiring lecturer notes from existing learning sources such as Ilearn and internet with $49.3 \%$ votes.

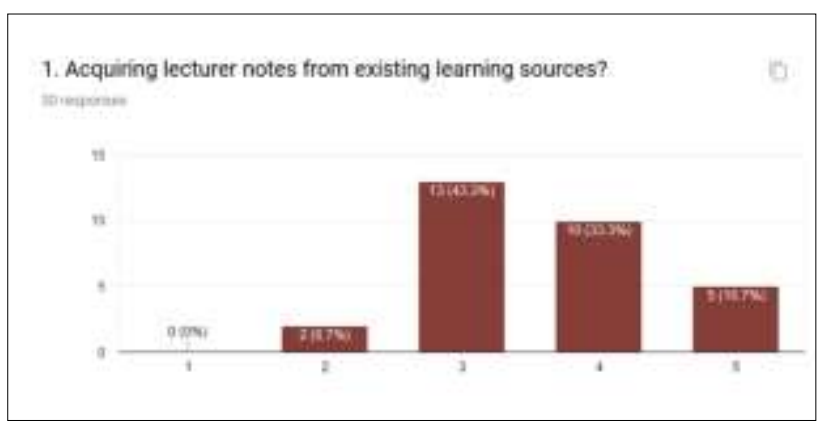

Figure 2. Satisfaction level in acquiring lecturer notes

Quite similar results could be seen for other satisfaction aspects (rank 4 and 5) such as $46.7 \%$ of the respondents were recorded satisfied with the existing Cartography learning sources in acquiring their tutorial questions. The satisfaction scale for acquiring lab sheets from existing learning sources are 50\% votes, which means the respondent are very satisfied in acquiring their lab sheets using the current learning system. The respondents were biting very satisfied in acquiring past examination questions with $73.4 \%$ votes.

Next, respondents were asked about their opinion on developing the proposed Cartography learning system. Based on Figure 3, the respondents were questioned either they were demanding or not on developing an integrated learning system for Cartography subject. Most of the respondents were responding that they agreed to have an integrated Cartography learning platform in order to ease the students for their learning purpose with majority vote which is $86.7 \%$ votes.

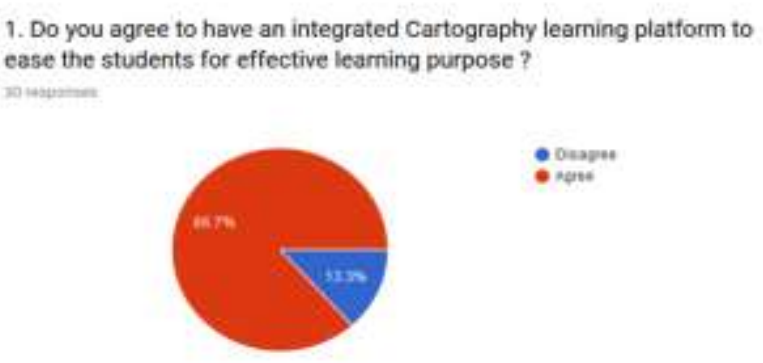

Figure 3. Respondents view to developing proposed learning systems
Figure 4 reveals the respondents' suggestion on the learning material and method to be equipped with the proposed learning system. The suggestion exceeds more than the half of the number of the respondents' votes. The requirements that need to be developed in the proposed system are note with $80 \%$, tutorial questions with $60 \%$, and lab sheets with $66.7 \%$, past examination questions with $73.3 \%$, assignments with $53.3 \%$, and free software and data sources with $60 \%$ and lastly multimedia learning with $70 \%$.

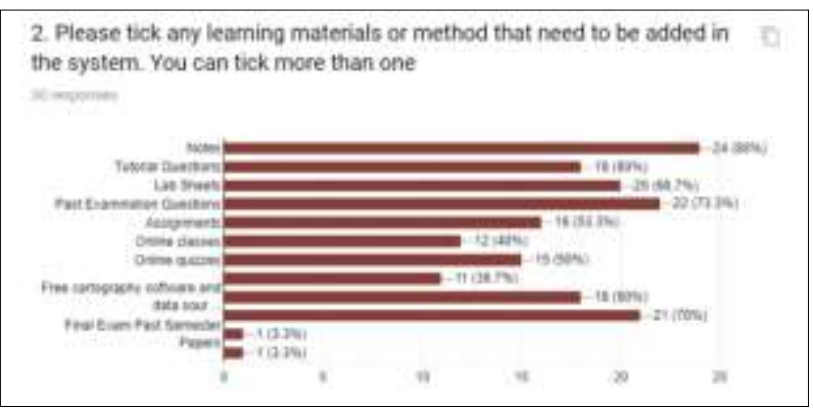

Figure 4. Requirement for the proposed learning system

Last but not least, the respondents were asked about their suggestions and ideas in order to improve or better the system. This additional suggestion could be used for future improvement in the learning Cartography system. The suggestions include providing independent online quiz or test, tutorials for software installement and laboratory works, free data collection or gallery and industrial collaboration for more particular task and exhibition..

\subsection{Design and Development the Proposed System}

This step enables the system to be established by migrating the data and components to the new system towards ensuring that the web application works correctly and smoothly. In fact, this web application has been developed based on the user requirement in the first objective which the respondent gave their opinion and ideas to ensure the system meet their desire.

\subsection{Elements and Functions of Integrated Learning Materials for Cartography}

In order to fulfil the needs of the web map application in helping students in their study of Cartography subject, Integrated Learning System for Cartography has been developed by using WordPress where it is a content management system based on PHP and MySQL that is usually used with. The features include a plugin architecture and a template system, referred to inside the WordPress Themes which able to design the interface of the system, add and edit the data of Cartography subject learning materials. Several testing procedures on this web map application has been carried out as developer want it to function smoothly. This sub-section will explain all the features and functions available on the Integrated Learning System for Cartography. 
In the main page of the system. It has two Buttons which are the three-line button and mouse button. The three line button is the menu widget. The user can click the button to pop out the menu list. The mouse button animation indicates the user to scroll down. Figure 5 shows the list of the main menus. The user can either scroll down or click on the menu list to reach the content page. The page will automatically open at the new tab.
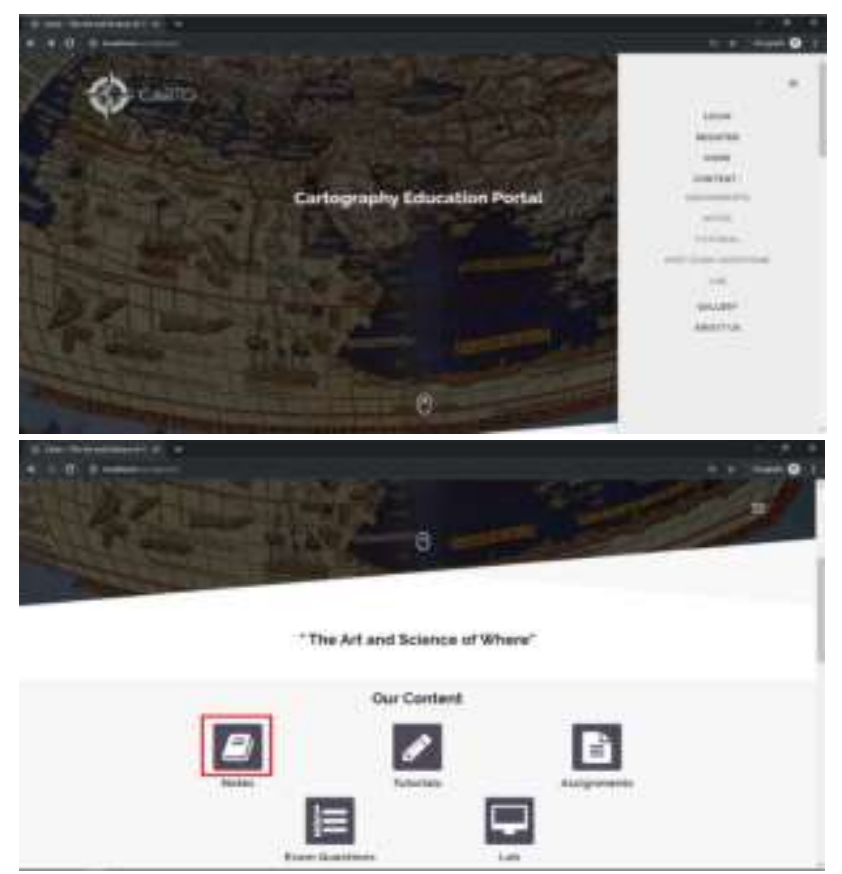

Figure 5. Main menu list

User can scroll down on the main menu page to go to the content section. The primary content of this integrated learning system of Cartography is based on the previous study of the user requirement for the proposed system. The content consists of 5 learning materials for the Cartography subject which are lecturer notes, tutorial questions, assignments, past semester exam questions and lab sheets. The user can click on the button that represent the symbol of the learning material to go to the desired page. As an example, the user can click the Notes button to acquiring notes from the system. It will bring the user to the Notes page. On the notes page, there is a list of downloadable content which is lecturer notes for Cartography subject. To download, user can click on the name of the notes and it will automatically download the content directly to the user platform either using a computer of a smartphone. This same step can be applied to the other content page.

The other element in the portal is gallery where images and videos about Cartography was shared on the gallery page. The user can click the click to view more button to explore more images and videos on the gallery page. At the gallery page, there are two sections. The first section is images section and the second section is videos section. The user can explore all the images and videos to increase their general knowledge about Cartography. The last section on the main menu page is the Newsfeed. Any news or event related about Cartography subject that occur either at the university or outside of the university will be shared on the Newsfeed section. In Menu of About us page, it shows the information about this integrated learning system for Cartography are shown in the About Us page. The user of this application could know detail description of the application such as the platform used to develop this application, the current version of this app and the developer or owner behind the application.

\subsection{Testing and Evaluating of Integrated Learning Materials Portal for Cartography}

The developer goes through a number of testing phase for the system on the computer to see the interface of the system is running and display properly or not. Since the web application still not publish in the server, which is the system is still in the local host server. A demo has been given to the user on how to use the system and the system was handed to the user to evaluate the system. The system has been evaluated from respondents who consist of the current student's semester 7 who are learning the Cartography subject (Figure 6). The system is displayed during the demo and being tested by the target user in order to give their opinion regarding the effectiveness of the integrated learning system of Cartography as shown in the figure below.

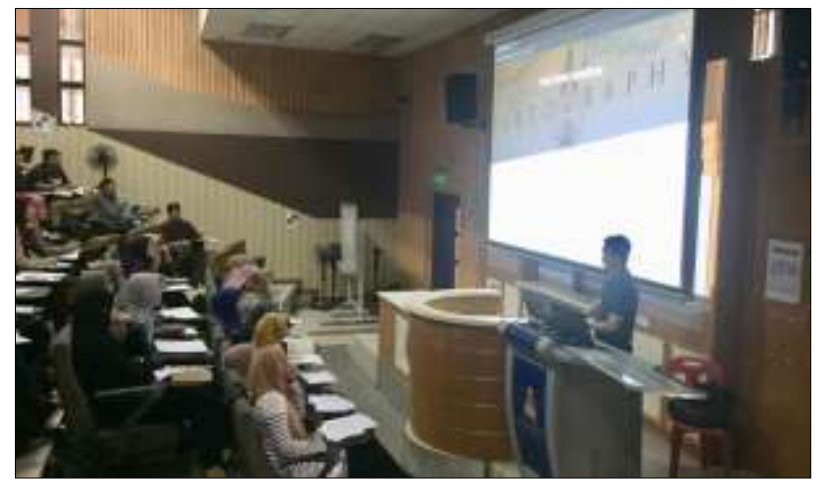

Figure 6. System testing with the UiTM Surveying Science and Geomatics students

The evaluation questions are given to the target user to rate their satisfaction level on the previous learning system and the integrated learning system of Cartography to make comparison between those two systems. The satisfaction level was determined by numbers from 1 to 5 as an interval scale. Starting from very dissatisfied followed by Not Satisfied (1), Slightly Satisfied, Satisfied, Very Satisfied and Extremely Satisfied (5). For the evaluation result, it can be seen that most all of the satisfaction level the proposed system is at level 4 and 5 which indicate the user are very satisfied and extremely satisfied with the system to be compared with the 
previous system that earn lower satisfactory result where most of the satisfaction level are a moderate. As a positive result was delivered, this system is able to assist students in order to give the best satisfaction for acquiring their learning material for Cartography subject. The respondent also been asked if they would use again in future as the results shows mostly all of them given the respondents strongly agreed and willingly to use to help their study not only in the subject but also in other SUG subjects.

\section{References}

This integrated learning portal for Cartography course was specially developed for assisting the UiTM Geomatics students in gathering all the learning materials in one platform. The portal has not only fulfilled the student requirement, but also towards achieving education 4.0 vision, which students can learn and identify the source the skills and knowledge. The portal offers a user friendly and easy-free platform, including online notes, assignments, lab work sheets, past examination question and others. With the rapid development of current technologies and industrial revolutionaries (IR), it is not wrong to say that this portal is needed by the students to enhance their understanding on the subject and to keep up with the mushroom growth modern technologies and new generation style of acquiring knowledge. This beneficial prototype has potential to be used by the students, hence the next steps need be added with other essential functions and be applied public domain server from the university.

\section{Acknowledgements}

The authors express their acknowledgements to the UiTM FSPU Cartography Students in 2019 and 2020 for their support during the development of the portal.

\section{References}

Abdul Basir, B. and Abdul Rasam, A. R. (2019). Evaluating Potential Free Software For Web-Based Multimedia Cartography, Int. Arch. Photogramm. Remote Sens. Spatial Inf. Sci., XLII-4/W16, 3-9, https://doi.org/10.5194/isprs-archives-XLII-4-W16-32019

Anthony C. Robinson, Joseph Kerski, Erin C. Long, Heng Luo, David DiBiase \& Angela Lee (2015) Maps and the geospatial revolution: teaching a massive open online course (MOOC) in geography, Journal of Geography in Higher Education, 39:1, 65-82, DOI: 10.1080/03098265.2014.996850.

Arani, O. K. (2001). Researching computer self-efficacy. International Education Journal, 2(4), 17-25.

Aziz Hussin, A. (2018). Education 4.0 Made Simple: Ideas For Teaching. International Journal of Education and Literacy Studies, 6(3), 92. https://doi.org/10.7575/aiac.ijels.v.6n.3p.92

Carlos Carbonell Carrera, Jose Luis Saorin Perez \& Jorge de la Torre Cantero (2018) Teaching with AR as a tool for relief visualization: usability and motivation study, International Research in Geographical and Environmental Education, 27:1, 69-84, DOI: 10.1080/10382046.2017.1285135.

Cheng, K., A (2006) Research Study on Students' Level of Acceptance in Applying E-Learning for Business Courses - A Case Study on a Technical College in Taiwan. Journal of American Academy of Business. Volume 8. Number 2. pp: 265-270.

Drucker, P., 2000. Need to Know - Integrating e-learning with High Velocity Value Chains. Delphi Group White Paper. www.delphigroup.com

Ethan Dunwill (2016). 4 Changes That Will Shape the Classroom Of The Future: Making Education Fully Technological https://elearningindustry.com/4-changeswill-shape-classroom-of-the-future-making-education-

fully-technological

Ertmer, P.A. (1999). Addressing first-and second-order barriers to change: Strategies for technology integration. Educational Technology Research and Development, 47(4), 47- 61.

Frančula,. N. and Lapaine, M. (2010). Open Contents Modules Available for E-Learning Multimedia Cartography and Location Based Services. Kartografija i Geoinformacije . 9(14):192-193.

FitzPatrick, T. (2012) "Key Success Factors of eLearning in Education: A Professional

Development Model to Evaluate and Support eLearning", US-China Education Review, 2012, A 9, 2012, 789-795.

German Giovanni Vargasa and Luz Angela Rocha (2018). How to learn Thematic Cartography in the context of Geosciences and Engineering? Towards a new pedagogical proposal. Proceedings of the International Cartographic Association. https://doi.org/10.5194/ica-proc-1-119-2017.

Guha, A.S. and Maji, S. (2008). E-Learning: The Latest Spectrum In Open And Distance Learning. Social Responsibility Journal 4(3):297-305. DOI: 10.1108/17471110810892820.

Fred Meyer (2018) "WordPress is a Factory: A Technical Introduction" http://wpshout.com/courses/learnwordpress-developement-the-basic course/wordpressis-a-factory/

Imran, M. (2017). WordPress: A Versatile Tool for Managing Contents. 8(2), 786-789.

Shteiman, B. (2014). Why CMS platforms are breeding security vulnerabilities. Network Security, 2014(1), 7-9. https://doi.org/10.1016/S1353-4858(14)70006-6

Jazdi, N, (2014), Cyber physical systems in the context of Industry 4.0. In Proceedings of the 2014 IEEE International Conference Automation, Quality and Testing, Robotics (AQTR), Cluj-Napoca, Romania, 2224 May 2014; pp. 1-4. 
Lasi, H.; Fettke, P.; Kemper, H.-G.; Feld, T, (2014), Hoffmann, M. Industry 4.0. Bus. Inf. Syst. Eng. 2014, 6, 239-242. https://doi.org/10.1007/s12599-014-0334-4

Lee, M., Yun, J. J., Pyka, A., Won, D., Kodama, F., Schiuma, G., ... Jung, K. (2018). How to Respond to the Fourth Industrial Revolution, or the Second Information Technology Revolution? Dynamic New Combinations between Technology, Market, and Society through Open Innovation. https://doi.org/10.3390/joitmc4030021

Liu, S., Guo, D., Sun, J., Yu, J, and Zhou, D. (2020). MapOnLearn: The Use of Maps in Online Learning Systems for Education Sustainability. Sustainability. 12(17):7018. https://doi.org/10.3390/su12177018

Matt, M.(2015) "State of the Word 2013" https://wordpress.tv/2013/07/29/matt- mullenweg-stateof-the-word-2013/

Marion, W., Susanne, B. and Joël, F. (2005). E-Learning Materials In Gis-Technology And Cartography Towards An Open-Content Solution. XXII International Cartographic Conference (ICC 2005)

MinHwa Lee, (2018), How to Respond to the Fourth Industrial Revolution, or the Second information Technology Revolution? Dynamic New Combinations between Technology,Market, and Society through Open Innovation http:// doi:10.3390/joitmc4030021

Moris, Z. (2018). Mobile Learning (M-Learning) Concept and Development of an App for the Alpine Cartographic Field School. Degree of Master of Science (M.Sc.), Germany.

Omar, M.F., Abdul Rasam, A.R., N Mohamed Saraf, N Md Saad and N Khalid. (2021). E-Atlas of Health in Selangor, Malaysia. IOP Conf. Series: Earth and Environmental Science $767 \quad$ (2021) 012006. doi:10.1088/1755-1315/767/1/012006.

Schwab, K. (2016). The Fourth Industrial Revolution: what it means, how to respond.

Accessed from https://www. weforum.org/agenda/2016/01/the-fourth-industrial-revolution-what-it-means-and-how-to-respond

Setapa, M. (2012). 3rd International Conference On Business And Economic Factors That Affect Student Performance: The Implementation Of The I-Learn At A Local University 3rd International Conference On Business And Economic. (March), 2950-2967.

Shea, R.H. (2002), E-learning today-As an industry shakes out, the survivors offer no-frills education for grown-ups. U.S. News \& World Report. October 28, 2002

Singh, A. K., Yusoff, M. A., \& Win, N. (2009). A Comparative Study between Traditional Learning and E- Teaching \& Learning. Teaching and Learning Open Forum, (June 2016). Retrieved from https://www.researchgate.net/publication/46419957\%0 AA
Tapsir, S. H., \& Puteh, M. (2018). Framing Malaysian Higher Education 4.0.

Yun, J.J. (2017) Business Model Design Compass: Open Innovation Funnel to Schumpeterian New Combination Business Model Developing Circle; Springer: Cham, Switzerland

Wan Hairi, W. H. , Abdul Rasam, A.R., Noraain Mohamed Saraf, and Nafisah Khalid. (2021). Free and open GIS source software for spatial epidemiology and geospatial health in Malaysia: a comparative analysis of the software usability. International Journal of Advanced Technology and Engineering Exploration, $\begin{array}{ll}\text { Vol 8(78). } & \text {. }\end{array}$ http://dx.doi.org/10.19101/IJATEE.2020.762192.

Zhang, D., Zhao, J. L., Zhou, L., \& Nunamaker, J. F. (2004). Can e-learning replace classroom learning? Communications of the ACM, 47(5), 75-79. https://doi.org/10.1145/986213.986216 